\title{
AMACR Detection in Urine Samples. Lack of Clinical Application in Routine Practice
}

\author{
Ewa Malusecka ${ }^{1, *}$, Agnieszka Gogler ${ }^{2}$, Marzena Gawkowska-Suwinska ${ }^{3}$, Katarzyna Behrendt ${ }^{3}$, \\ Elzbieta Nowicka $^{3}$, Beata Smolska ${ }^{3}$ and Aleksander Zajusz ${ }^{3}$
}

\begin{abstract}
${ }^{1}$ Department of Radiotherapy, Maria Sklodowska-Curie Memorial Cancer Center and Institute of Oncology, Gliwice Branch, Wybrzeze Armii Krajowej 15, 44-101 Gliwice, Poland; ${ }^{2}$ Department of Tumor Biology, Maria SklodowskaCurie Memorial Cancer Center and Institute of Oncology, Gliwice Branch, Wybrzeze Armii Krajowej 15, 44-101 Gliwice, Poland; ${ }^{3}$ II Radiotherapy Clinic, Maria Sklodowska-Curie Memorial Cancer Center and Institute of Oncology, Gliwice Branch, Wybrzeze Armii Krajowej 15, 44-101 Gliwice, Poland
\end{abstract}

\begin{abstract}
PSA is still recognized as the best marker available for detection and treatment monitoring of prostate cancer. However limitations of PSA testing raise a need for other valuable cancer markers. Expression of AMACR protein is recognized as a potential predictive marker, highly competitive to the PSA. Based on preliminary study on AMACR urine detection, the urine without prior prostate manipulations was tested for AMACR detection and radiotherapy treatment monitoring of prostate cancer. Urine samples derived from 57 patients were analyzed. Mainly, there were prostate cancer patients -43 cases, benign prostate disease -4 cases and lung ( 7 cases) as well as urinary bladder ( 3 cases) cancer patients. Samples were examined for AMACR and PAP staining using Western blot. In none of the prostate cancer patients AMACR protein was identified. However in $1 / 3$ of urine samples of bladder cancer patients AMACR protein was detected. PAP staining performed on the same samples was positive in all prostate but not in other cancer (lung, bladder) cases. Testing of the urine without prior prostate manipulations (massage, USG, biopsy) is the most probable reason for the Western blot AMACR negative results. On the other hand positive AMACR staining in bladder cancer raise the possibility of false positive results. Therefore urine AMACR testing in prostate cancer cannot be recommended.
\end{abstract}

Keywords: AMACR, biopsy, prostate cancer, PSA, urine.

\section{INTRODUCTION}

PSA (prostate serum antigen) is a glycoprotein produced by prostate glandular epithelial cells. Although PSA measurement is recognized as the best available serum tumor marker, it has some limitations as well [1]. PSA is prostate gland-specific, but it turned out to be not prostate cancerspecific. Elevated PSA serum levels is detected in patients with BPH (benign prostatic hyperplasia), prostatitis, and as a result of some drug treatment or prostate damage [2-4]. As a consequence, wide application of PSA screening led to overdiagnosis of prostate cancer. Implementation of other tests, with well established sensitivity and specificity is needed for unambiguous diagnosis. One of the genes/proteins examined so far, with great recognition, is AMACR (alphamethylacyl CoA racemase), enzyme that is involved in peroxisomal $\beta$-oxidation of dietary branched-chain fatty acids. Radiotherapy does not change AMACR level, which implies effectiveness of its testing for monitoring of post-treatment recurrence [5]. Conflicting data exist on hormonotherapy effect on AMACR expression. Kuefer et al. [6] described no effect of hormone therapy, while Suzue et al. [7] showed significant reduction of AMACR expression following hormone therapy.

Address correspondence to this author at the Department of Radiotherapy, Maria Sklodowska-Curie Memorial Cancer Center and Institute of Oncology, Gliwice Branch, Wybrzeze Armii Krajowej 15, 44-101 Gliwice, Poland; Tel: +48 3227896 47; Fax: +48 3223135 12;

E-mail: maluseck@io.gliwice.pl
AMACR gene is overexpressed 55 times as cancerous compared to prostate normal tissue [8-11]. Significance of AMACR alteration is not established so far it is only known that enzyme coded by the overexpressed gene is functional. Variants of AMACR coding gene as well as alternatively spliced form are described [12-14].

Immunohistochemical studies have shown that, AMACR protein level is elevated in prostate cancer glandular epithelium, compared with its expression in normal or benign prostate. AMACR protein, assessed by Western blot, showed elevated level up to 34 times in cancerous tissue [15]. Reports on AMACR positivity in various Gleason scores are conflicting; from no relationship to positive association with Gleason score [11]. Particularly important, benign glands (positive for $34 \mathrm{bE} 12$ - basal cell marker) adjacent to the malignant are negative for AMACR immunoreactivity [11]. It was shown, by immunohistochemistry that AMACR is present in atrophic prostate glands, although with weak or moderate staining intensity $[16,17]$ and/or other premalignant and pathologic changes $[18,19]$.

As exfoliated prostate cells can be detected in the urine of men with prostate cancer, urine-based tests are potential screening tool for disease detection and/or monitoring. Urine tests have the advantage of being noninvasive in comparison to other methods of material acquiring. Rogers et al. [20] reported the feasibility of a novel urinary test for prostate cancer based on the presence of AMACR protein in voided urine specimens obtained after prostate biopsy. This prelimi- 
nary data include only small number of patients and are based on post-biopsy urine analysis. Therefore we wanted to examine the possibility if urine AMACR from patients without prior biopsy of prostate or other manipulations, can be exploited in cancer detection or monitoring of radiotherapy treatment.

\section{MATERIALS AND METHODS}

\section{Patients}

Clinical material consisted of 57 patients. All men provided an informed consent approved by Internal Bioethical Committee. Examined group consisted of benign prostate disease patients (4 cases) (outpatients only) and cancer patients (43 cases). For prostate patients diagnosis (adenocarcinoma or benign disease) was established on the basis of biopsy. PSA serum level was known for all prostate patients and Gleason score was known for prostate cancer patients. Negative control group consisted of lung (7 cases) and urinary bladder (3 cases) cancer patients. Detailed patients characteristic is given in Table $\mathbf{1}$.

Urine was taken before biopsy (if biopsy was done on the same day) or after biopsy (if biopsy was done long before (months) urine collection). Biopsy outcome was known at the time of enrolling patient to the analysis.

\section{URINE COLLECTION AND PROTEIN EXTRACTION}

Voided urine samples were collected before treatment and were preceded at least 30 minutes after the collection. Samples were coded and immediately cooled on ice. Urine was obtained independently of TRUS (Transrectal Ultrasound Scan) guided biopsy.

Urine centrifugation and lysis conditions were essentially the same as described by Rogers et al. [20] with slight modifications. For preliminary microscopic examination, a sample $(50 \mathrm{ml})$ of well-mixed urine was centrifuged in a test tube at low speed $(700 \mathrm{~g})$ for 5-10 minutes. The microscopic analysis was performed (under low power) for crystals, casts, squamous epithelial cells, and other objects. The pellet was lysed in ice-cold protein extraction buffer containing: $4 \%$ SDS, 0,1M Tris $\mathrm{pH} 7.4,1 \mathrm{mM}$ EDTA, cocktail of proteases inhibitors: bestatin, leupeptin, aprotinin (1:100). Subsequently mixture was centrifuged $\left(14000 \mathrm{rpm} / 10 \mathrm{~min}, 4^{\circ} \mathrm{C}\right)$. Total protein content was measured with Bradford technique (Bradford Protein Assay, BioRad Laboratories, Richmond, CA).

\section{LNCAP CELL LINE CULTURE}

$\mathrm{LNCaP}$, androgen-responsive $\mathrm{CaP}$-derived cell line with elevated AMACR protein level was obtained from ECACC
(Salisbury, UK). Cells were grown under standard culture conditions (humidified atmosphere containing $5 \% \quad \mathrm{CO}_{2}$ at $37^{\circ} \mathrm{C}$ ) in RPMI 1640 medium (Sigma, St. Louis, MO), supplemented with $10 \%$ (v/v) FBS (Gibco, Grand Island, NY) and gentamycine (Krka, Novo Mesto, Slovenia). Confluent cells were trypsinized and lysed with protein extraction buffer (composition the same as described above).

\section{WESTERN BLOT ANALYSIS}

Equal amounts $(50 \mu \mathrm{g})$ of $\mathrm{LNCaP}$ and urine protein extracts were separated electrophoretically in 10\% SDSpolyacrylamide gels in the presence of commercially available protein weight marker (SM-6071, Fermentas, Hanover, $\mathrm{MD})$, and then transferred to nitrocellulose membrane. Membrane was blocked in 5\% unfatted milk in TBS supplemented with $0,05 \%$ Tween 20 , and subsequently incubated overnight at $4{ }^{\circ} \mathrm{C}$ with rabbit anti-AMACR monoclonal antibody, at dilution 1:300 (Chemicon International, Billerica, USA). After washing, immunoreactive AMACR protein was visualized with $\mathrm{ABC}$ Vectastain kit (Vector Laboratories, Burlingame, CA) and 3,3'-diaminobenzidine (DAB) (Sigma, St. Louis, MO).

Since in urinary sediments not only prostate cells but also urothelial cells are present - to limit the AMACR-test for the prostate origin, anti-PAP (prostatic acid phosphatase) mouse antibody (at dilution 1:500) (Sigma, St. Louis, MO) has been used as control staining.

\section{RESULTS}

Urine samples derived from 57 patients were analyzed for AMACR protein. In prostate cancer and benign tumor patients' urine samples AMACR was not detected.

In none of the urine sample derived from lung cancer patients (negative control) AMACR protein was identified. In 1/3 urine sample of bladder cancer patients, AMACR protein was detected. In this sample AMACR level was higher than that found in $\mathrm{LNCaP}$ protein extract (Fig. 1).

PAP staining performed on the same samples was positive in all prostate samples (irrespectively of PSA level and Gleason score) and LNCaP cell line and negative in bladder and lung cancer urine samples (Fig. 1).

AMACR and PAP staining were positive in control LNCaP cell line lysate.

\section{DISSCUSION}

The present study is based on the report of Rogers et al. [20] on potential utility of AMACR protein assay in urine of post-biopsy patients. We asked whether urine AMACR pro-

Table 1. Patients' Description

\begin{tabular}{|l|l|l|l|}
\hline Diagnosis & Number of Patients (57 Total) & PSA Level Range (Median) & Gleason Score Range (Median) \\
\hline \hline Prostate benign disease & 4 & $1.37-40.39(40.4)$ & \\
\hline Prostate cancer & 43 & $0.47-92.29$ & $2-9(5: 2+3)$ \\
\hline Lung cancer & 7 & & \\
\hline Bladder cancer & 3 & & \\
\hline
\end{tabular}




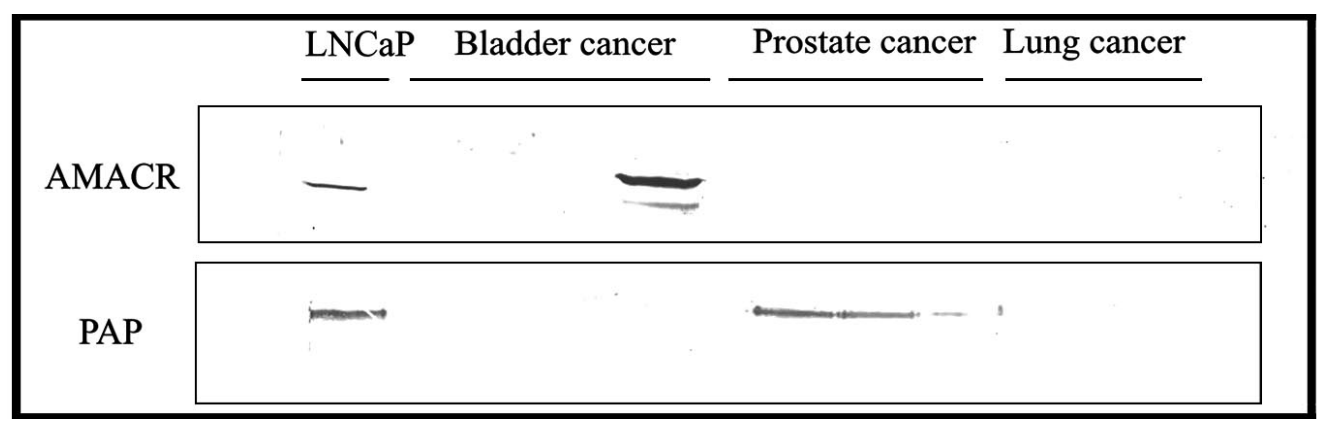

Fig. (1). Western blot analysis of AMACR and PAP proteins.

tein level with no prior-biopsy might be used for detection or monitoring of prostate cancer patients, especially those with intermediate PSA serum level.

Rogers et al. [20] claimed that mechanic damage of the prostate gland (caused by biopsy and transrectal USG) is the possible reason for prostate gland irritation and epithelial cells shedding to the urine. This is the most probable reason why our Western blots of non post-biopsy specimens were negative. At the same time total protein loading was even higher in our electrophoresis then that described by Rogers et al. [20]. Positive staining in control LNCaP sample as well as in one of the bladder cancer urine sample is a confirmation of methodological correctness of our study.

Since presence of AMACR protein in bladder cancer is reported $(30 \%$ urinary bladder mucosal epithelial cells in IHC tests are AMACR-positive) [21, 22], the results obtained are not false positives. Nevertheless AMACR testing is not utilized as a marker in bladder cancer, despite the recently reported correlation with histological grading in noninvasive bladder cancer [23].

Since AMACR diagnostic utility in histological material is well known, its detection ability has been studied on protein (Western blot) and mRNA level (RT-PCR) in nonhistologic samples (serum). By Western blot low level of circulating AMACR protein was found in sera of 3/40 prostate cancer patients, irrespectively of PSA serum level [24]. This low detection rate was ascribed either to not sufficient for sensitivity of Western blot or low of AMACR secretion. In the same group of patients presence of AMACR autoantibodies was examined. AMACR humoral response was found in majority of cancer patients and low number of matched for age, healthy controls. Specificity and sensivity of this test were $71.8 \%$ and $61.6 \%$, respectively, but there was no relationship with PSA level, Gleason grade, stage or biochemical recurrence. The humoral response against AMACR was also statistically significant considering patients with intermediate PSA levels (4-10 ng/mL) and it was suggested that AMACR testing can be used in combination with serum PSA [20]. Different approach was proposed by Zehentner et al. [25]. They tested cancer patients and controls sera by means of qRT-PCR for AMACR content. Using some mathematical methods based on AMACR copy number they were able to distinguish between benign prostate disease and cancer in remission and organ-confined or metastatic cancer. However for individual patient the AMACR copy number was not informative. Finally, Zehentner et al. [25] performed urine sediment testing for AMACR expression. In this pilot study, limited to 11 patients, urine sample was obtained after prostate massage. Various AMACR expression levels were detected without any trend observed. Number of samples was too small to draw any conclusion.

As prostate cells can be detected in the urine of men with prostate cancer, urine-based diagnostic tests have the advantage of being non-invasive. Although urine-based screening test for PCA3 expression has been documented, the feasibility of testing based on other markers has not been rigorously evaluated [26]. Developments in molecular techniques provide new tools that lead to the identification of hundreds of genes and proteins that are believed to be relevant for the development of prostate cancer. Numerous promising prostate cancer biomarkers have been identified, including genes and proteins specific for prostate malignances [10,27].

\section{CONCLUSIONS}

Western blot AMACR testing in urine samples of prostate cancer patients cannot be recommended in clinical practice. False negative results (AMACR negative staining, biopsy outcome positive for prostate cancer) and false positive results in bladder cancer make urine samples unsuitable for accurate diagnosis and treatment monitoring.

\section{REFERENCES}

[1] Schröder FH. PSA screening--a review of recent studies. Eur J Cancer 2009; Suppl 1: 402-4.

[2] Nadler RB, Humphrey PA, Smith DS, et al. Effect of inflammation and benign prostatic hyperplasia on elevated serum prostate specific antigen levels. J Urol 1995; 2(Pt 1): 407-13.

[3] Tarhan F, Orçun A, Küçükercan I, et al. Effect of prostatic massage on serum complexed prostate-specific antigen levels. Urology 2005; 6: 1234-8.

[4] Collins GN, Martin PJ, Wynn-Davies A, et al. The effect of digital rectal examination, flexible cystoscopy and prostatic biopsy on free and total prostate specific antigen, and the free-to-total prostate specific antigen ratio in clinical practice. J Urol 1997; 5: 1744-7.

[5] Yang XJ, Laven B, Tretiakova M, et al. Detection of alphamethylacyl-coenzyme A racemase in postradiation prostatic adenocarcinoma. Urology 2003; 62: 282-6.

[6] Kuefer R, Varambally S, Zhou M, et al. Alpha-Methylacyl-CoA racemase: expression levels of this novel cancer biomarker depend on tumor differentiation. Am J Pathol 2002; 161: 841-8.

[7] Suzue K, Montag AG, Tretiakova M, Yang XJ, Sahoo S. Altered expression of alpha-methylacyl-coenzyme A racemase in prostatic adenocarcinoma following hormone therapy. Am J Clin Pathol 2005; 123: 553-61.

[8] Xu J, Stolk JA, Zhang X, et al. Identification of differentially expressed genes in human prostate cancer using subtraction and microarray. Cancer Res 2000; 60: 1677-82.

[9] Luo J, Zha S, Gage WR, et al. Alpha-methylacyl-CoA racemase: a new molecular marker for prostate cancer. Cancer Res 2002; 62: 2220-6.

[10] Rubin MA, Zhou M, Dhanasekaran SM, et al. A-Methylacyl coenzyme A racemase as a tissue biomarker for prostate cancer. JAMA 2002; 287: 1662-70. 
[11] Jiang Z, Wu CL, Woda BA, et al. Alpha-methylacyl-CoA racemase: a multi-institutional study of a new prostate cancer marker. Histopathology 2004; 45: 218-25.

[12] Zheng SL, Chang BL, Faith DA, et al. Sequence variants of alphamethylacyl-CoA racemase are associated with prostate cancer risk. Cancer Res 2002; 62: 6485-8.

[13] Ferdinandusse S, Denis S, Clayton PT, et al. Mutations in the gene encoding peroxisomal alpha-methylacyl-CoA racemase cause adult-onset sensory motor neuropathy. Nat Genet 2000; 2: 188-91.

[14] Mubiru JN, Valente AJ, Troyer DA. A variant of the alpha-methylacyl-CoA racemase gene created by a deletion in exon 5 and its expression in prostate cancer. Prostate 2005; 65: 117-23.

[15] Jiang Z, Woda BA, Rock KL, et al. P504S: a new molecular marker for the detection of prostate carcinoma. Am J Surg Pathol 2001; 25: 1397-404.

[16] Farinola MA, Epstein JI. Utility of immunohistochemistry for alpha-methylacyl-CoA racemase in distinguishing atrophic prostate cancer from benign atrophy. Hum Pathol 2004; 35: 1272-8.

[17] Adley BP, Yang XJ. Alpha-methylacyl coenzyme A racemase immunoreactivity in partial atrophy of the prostate. Am J Clin Pathol 2006; 126: 849-55.

[18] Evans A. A-Methylacyl CoA racemase (P504S): overview and potential uses in diagnostic pathology as applied to prostate needle biopsies. J Clin Pathol 2003; 56: 892-7.

[19] Varma M, Jasani B. Diagnostic utility of immunohistochemistry in morphologically difficult prostate cancer: review of current literature. Histopathology 2005; 47: 1-16.
[20] Rogers CG, Yan G, Zha S, et al. Prostate cancer detection on urinalysis for alpha methylacyl coenzyme a racemase protein. J Urol 2004; 172: 1501-3.

[21] Zhou M, Chinnaiyan AM, Kleer CG, Lucas PC, Rubin MA. AlphaMethylacyl-CoA racemase: a novel tumor marker over-expressed in several human cancers and their precursor lesions. Am J Surg Pathol 2002; 26: 926-31.

[22] Jiang Z, Fanger GR, Woda BA, et al. Expression of alphamethylacyl-CoA racemase (P504s) in various malignant neoplasms and normal tissues: a study of 761 cases. Hum Pathol 2003; 34: 792-6.

[23] Gunia S, May M, Scholmann K, et al. Expression of alphamethylacyl-CoA racemase correlates with histopathologic grading in noninvasive bladder cancer. Virchows Arch 2008; 453: 165-70.

[24] Sreekumar A, Laxman B, Rhodes DR, et al. Humoral immune response to alpha-methylacyl-CoA racemase and prostate cancer. $\mathrm{J}$ Natl Cancer Inst 2004; 96: 834-43. Erratum in: J Natl Cancer Inst 2004; 96: 1112 .

[25] Zehentner BK, Secrist H, Zhang X, et al. Detection of alphamethylacyl-coenzyme-A racemase transcripts in blood and urine samples of prostate cancer patients. Mol Diagn Ther 2006; 10: 397 403 .

[26] Laxman B, Morris DS, Yu J, et al. A first-generation multiplex biomarker analysis of urine for the early detection of prostate cancer. Cancer Res 2008; 68: 645-9.

[27] de Kok JB, Verhaegh GW, Roelofs RW, et al. DD3(PCA3), a very sensitive and specific marker to detect prostate tumors. Cancer Res 2002; 62: 2695-8.

(C) Malusecka et al.; Licensee Bentham Open.

This is an open access article licensed under the terms of the Creative Commons Attribution Non-Commercial License (http://creativecommons.org/licenses/ by-nc/3.0/) which permits unrestricted, non-commercial use, distribution and reproduction in any medium, provided the work is properly cited. 